\title{
Decision Gate Process for Assessment of a NASA Technology Development Portfolio
}

\author{
Rajiv Kohli ${ }^{1}$ \\ The Aerospace Corporation, Houston, TX, 77058 \\ Julianna L. Fishman ${ }^{2}$ \\ Jacobs Technology, Inc., NASA Ames Research Center, Moffett Field, CA, 94035 \\ and \\ Mark J. Hyatt ${ }^{3}$ \\ NASA Glenn Research Center, Cleveland, OH, 44135
}

\begin{abstract}
The NASA Dust Management Project (DMP) was established to provide technologies (to Technology Readiness Level (TRL) 6) required to address adverse effects of lunar dust to humans and to exploration systems and equipment, to reduce life cycle cost and risk, and to increase the probability of sustainable and successful lunar missions. The technology portfolio of DMP consisted of different categories of technologies whose final product was either a technology solution in itself, or one that contributes toward a dust mitigation strategy for a particular application. A Decision Gate Process (DGP) was developed to assess and validate the achievement and priority of the dust mitigation technologies as the technologies progress through the development cycle. The DGP was part of continuous technology assessment and was a critical element of DMP risk management. At the core of the process were technology-specific criteria developed to measure the success of each DMP technology in attaining the technology readiness levels assigned to each decision gate. The DGP accounts for both categories of technologies and qualifies the technology progression from technology development tasks to application areas. The process provided opportunities to validate performance, as well as to identify non-performance in time to adjust resources and direction. This paper describes the overall philosophy of the DGP and the methodology for implementation for DMP, and describes the method for defining the technology evaluation criteria. The process is illustrated by example of an application to a specific DMP technology.
\end{abstract}

\section{Introduction}

$\mathrm{T}$ HE NASA Dust Management Project (DMP) initiated in $2007^{4}$ was established as an element of NASA's Exploration Technology Development Program (ETDP) chartered to address the relevant high priority technology needs of multiple elements within the Constellation Program and other ETDP projects. The DMP provided technologies (to Technology Readiness Level (TRL) 6) required to mitigate adverse dust effects to humans

\footnotetext{
${ }^{1}$ Senior Project Engineer, Civil and Commercial Operations.

${ }^{2}$ Manager, Technology Integration Agent, MS 202-3.

${ }^{3}$ Deputy Project Manager, Cryogenic Propellant Storage \& Transfer, MS 77-5.

${ }^{4}$ DMP was terminated in September 2010 as part of the decision to terminate the Constellation Program. All technology development efforts and DGP assessments discussed here date to September 2010. References to cancelled and/or restructured programs and projects as they related to the DMP exist in this document for the purposes of illustrating former programmatic relationships. At the time of this writing it is unknown which former DMP technology development projects have been continued within other programs, but given that they are not continued under the auspices of the DMP, descriptions are written in the past tense.
} 
and to exploration systems and equipment, with the anticipated results being reduced life cycle cost and risk, and increased probability of sustainable and successful human exploration missions.

The development and implementation of a Decision Gate Process (DGP) to validate the achievement and priority of each DMP technology as it progressed through its development cycle was a critical element of DMP risk management. The TRLs defined by Mankins ${ }^{1}$ for application to NASA-developed technologies provided the basis for this process. At the core of the DGP are technology-specific criteria developed to measure the success of each technology at attaining the TRLs assigned to each decision gate. In all, four decision gates were delineated with TRLs 3 and 4 designated to DMP's technology development tasks and TRLs 5 and 6 designated to its application areas.

The DMP technology development portfolio consisted of two categories of technologies whose final product was either a technology solution in itself (e.g. mechanical components), or one that contributed toward a dust mitigation strategy (e.g. electrodynamic dust shield) for a particular application (e.g. surface power systems). The DGP accounted for both categories and qualified the technology progression from development starting at TRL 3 through to application. The process supported customer milestones by providing opportunities to validate performance as well as identify non-performance in time to adjust resources and direction.

This paper outlines the overall philosophy and methodology of the DGP and identifies the method by which core evaluation criteria for each technology category were defined, as well as the definition of specific criteria for each technology at a particular TRL. A description of the infrastructure and approach for implementation of the process is provided, and is illustrated by an example of application to a DMP technology.

\section{DMP Technologies and Application Areas}

Specific DMP technology development areas included mechanical systems, cleaning technologies, materials development, connectors, and thermal and power systems component development. The technology development tasks and application areas are listed in Table 1.

Table 1. DMP Technology Development Tasks and Application Areas

\begin{tabular}{|c|c|}
\hline \multicolumn{2}{|r|}{ Technology Development Tasks } \\
\hline Task & Scope \\
\hline $\begin{array}{l}\text { Mechanical } \\
\text { Components and } \\
\text { Mechanisms }\end{array}$ & $\begin{array}{l}\text { Develop mechanical components and mechanisms to include bearings, seals, and gears for } \\
\text { use in relevant surface assets. The technical approach included performance testing of } \\
\text { materials and mechanisms with the final product being development of mechanisms and } \\
\text { novel lubricants. }\end{array}$ \\
\hline Lotus Coatings & $\begin{array}{l}\text { Develop an overcoat coating that has anti-contamination and self-cleaning properties for use } \\
\text { as a dust mitigation method on various extravehicular activity (EVA), lunar surface system } \\
\text { (LSS), and Altair surfaces. The unique morphology of the coating was slated to help prevent } \\
\text { lunar regolith from adhering to coated surfaces and to facilitate dust } \\
\text { removal/decontamination of those Lotus-coated surfaces. }\end{array}$ \\
\hline SPARCLED & $\begin{array}{l}\text { SPARCLED (Space Plasma Alleviation of Regolith Concentrations in Lunar Environments } \\
\text { by Discharge) was composed of an electron beam source in the form of an electron gun. A } \\
\text { flood of electrons rapidly charged any regolith within the beam diameter with a sufficient } \\
\text { charge to mass ratio to rapidly disperse the dust particles via electrostatic repulsion. }\end{array}$ \\
\hline $\mathrm{CO}_{2}$ Shower & $\begin{array}{l}\text { To protect entry to an airlock and the habitat, the development of deployable, possibly } \\
\text { inflatable, dust isolation and removal zones was to be conducted using } \mathrm{CO}_{2} \text { snow shower } \\
\text { technology. }\end{array}$ \\
\hline $\begin{array}{l}\text { Electrodynamic } \\
\text { Dust Shield }\end{array}$ & $\begin{array}{l}\text { The electrodynamic dust shield (EDS) used alternating electric fields to dislodge, carry, and } \\
\text { deposit dust particles off and away from surfaces. The active EDS removed dust particles } \\
\text { and prevented dust accumulation on surfaces that needed protection, including solar panels, } \\
\text { in-situ resource utilization (ISRU) optical windows, helmet visors, optical systems, thermal } \\
\text { radiators, batteries, and boots. }\end{array}$ \\
\hline $\begin{array}{l}\text { Mitigation for } \\
\text { Radiators }\end{array}$ & $\begin{array}{l}\text { Determine the extent of degradation of thermal control surfaces for Altair and LSS } \\
\text { components by lunar dust and determine ways to effectively mitigate that degradation. }\end{array}$ \\
\hline $\begin{array}{l}\text { Dust Tolerant EVA- } \\
\text { Compatible }\end{array}$ & $\begin{array}{l}\text { Develop connectors (quick disconnects (QD) and umbilical systems) that can be repetitively } \\
\text { and reliably mated and de-mated during lunar surface EVA. }\end{array}$ \\
\hline
\end{tabular}




\begin{tabular}{|c|c|}
\hline Connectors & \\
\hline \multicolumn{2}{|r|}{ Application Areas } \\
\hline Area & Scope \\
\hline $\begin{array}{l}\text { Dust Tolerant EVA } \\
\text { connectors }\end{array}$ & $\begin{array}{l}\text { The objectives of this area were component level integration and testing of connectors } \\
\text { (quick disconnects and umbilical systems) that could be repetitively and reliably mated and } \\
\text { de-mated during lunar EVAs. These standardized interfaces would be required for structural } \\
\text { integrity and commodities transfer between linked surface elements. The scope included } \\
\text { small scale prototype development and component level integration. The components would } \\
\text { have been integrated into EVA suit and lunar surface system components. }\end{array}$ \\
\hline $\begin{array}{l}\text { Dust Mitigation for } \\
\text { Thermal Control } \\
\text { Surfaces }\end{array}$ & $\begin{array}{l}\text { Develop thermal radiator component level technologies to TRL } 6 \text { to address adverse lunar } \\
\text { soil effects. Scaled-up prototypes of thermal control surfaces with the required regolith } \\
\text { mitigation technologies would be fabricated and tested before infusion. Applicable DMP } \\
\text { technologies developed to address dust mitigation of thermal control surfaces included the } \\
\text { EDS, dust repellant materials, Lotus coatings, and other technologies developed by entities } \\
\text { involved in a separate Small Business Innovative Research (SBIR) program. }\end{array}$ \\
\hline $\begin{array}{l}\text { Dust Mitigation for } \\
\text { Surface Power } \\
\text { Systems }\end{array}$ & $\begin{array}{l}\text { Dust mitigation technologies for surface power system component level technologies (solar } \\
\text { panels, energy storage battery modules, interface plates, etc.) were being developed to TRL } \\
6 \text { in order to address adverse lunar soil effects. The regolith mitigation technologies would } \\
\text { be integrated into the surface power component subsystem and prototype demonstration } \\
\text { would be performed in a relevant environment. Applicable DMP technologies developed to } \\
\text { address dust mitigation of surface power systems include EDS, dust repellant materials, } \\
\text { Lotus coatings, and other technologies developed by entities involved in the SBIR program. }\end{array}$ \\
\hline $\begin{array}{l}\text { Dust Tolerant } \\
\text { Mechanical } \\
\text { Components }\end{array}$ & $\begin{array}{l}\text { Integration and testing of the mechanical component-level technologies identified above in } \\
\text { the mechanical components and mechanisms technology development task to TRL } 6 \text {. }\end{array}$ \\
\hline $\begin{array}{l}\text { Dust Mitigation for } \\
\text { ISRU Components }\end{array}$ & $\begin{array}{l}\text { Integration and testing of ISRU components (optical systems like windows, cameras, light } \\
\text { sources and sample recovery chambers) with embedded dust mitigation technologies to } \\
\text { minimize the adverse dust effects during lunar surface operations. Dust mitigation } \\
\text { technologies would be integrated into the ISRU component subsystem and prototype } \\
\text { demonstration would be performed in a relevant environment. DMP technologies developed } \\
\text { to address dust mitigation of ISRU surfaces include EDS, dust repellant materials, Lotus } \\
\text { coatings, and other technologies developed by entities involved in the SBIR program. }\end{array}$ \\
\hline $\begin{array}{l}\text { Dust Mitigation for } \\
\text { EVA Spacesuit } \\
\text { Systems }\end{array}$ & $\begin{array}{l}\text { Integration and testing of EVA components (visors, boots, gloves, Thermal Micrometeoroid } \\
\text { Garment (TMG) over garment, suit pressure garment) with embedded dust mitigation } \\
\text { technologies to minimize the adverse dust effects during lunar surface EVAs. DMP } \\
\text { technologies developed to address dust mitigation of EVA spacesuit systems include EDS, } \\
\text { dust repellant materials, Lotus coatings, and other technologies developed by entities } \\
\text { involved in the SBIR program. }\end{array}$ \\
\hline
\end{tabular}

\section{Need for a Decision Gate Process for DMP Technologies}

The DGP provided an objective mechanism for overall identification and evaluation of performing and nonperforming DMP technologies. The process offered frequent opportunities with multiple decision gates to weed out non-performing technologies before too many resources were invested in these technologies, and while there was time to identify an alternate technology or deviation from an earlier development plan. The DGP also provided an opportunity for DMP investments to demonstrate maturity at identified points and on schedule to instill customer confidence that each DMP deliverable met qualifying metrics at each step in its progression. The process also afforded a mechanism to identify the best performing, highest customer priority technologies, so that during times of budget reduction, investments could be allocated appropriately to ensure the most chance of success for those technologies.

\section{A. Description of the Decision Gate Process for DMP}

The process of utilizing decision gates is commonly employed in a wide range of applications to assess technology developments. The DGP developed specifically for the DMP is described in the following sections. 


\section{Generic Decision Gate Process}

The DGP developed and utilized by the DMP is based on the Technology Stage-Gate ${ }^{\mathrm{TM}}$ (TechSG ${ }^{\mathrm{TM}}$ ) described by Ajamian and Koen ${ }^{1}$ to manage technology development efforts when there is high uncertainty and risk surrounding the effort. The TechSG ${ }^{\mathrm{TM}}$ spans idea generation and development of a broad understanding of a technology that is required, through early technology development until it is decided whether a significant risk has been reduced in order for the particular technology to continue its development path. The TechSG ${ }^{\mathrm{TM}}$ process utilizes a series of gates or reviews where at each gate a certain deliverable or milestone is reviewed to determine whether it has been achieved. Deliverables for each subsequent gate may change due to the need to take a different approach given unexpected discoveries uncovered in the technology development process. The TechSG ${ }^{\mathrm{TM}}$ process brings together scientific, financial, and technological elements of a project to ensure that appropriate resources are invested into a technology investment according to progress made and knowledge gained, before product development may occur. TechSG ${ }^{\mathrm{TM}}$ is used to manage a technology development effort until agreed upon risks have been satisfied.

\section{Adaptation to DMP Projects}

The TechSG ${ }^{\mathrm{TM}}$ process was adapted for use by the DMP using the same general process elements, but expanded to include the review of TRL 3 technologies through to TRL 6 to allow for assessment of technology development tasks and application area projects, both of which comprise the DMP portfolio as noted earlier. Hence, the DMP DGP has two elements: a) an overall infrastructure similar to the TechSG ${ }^{\mathrm{TM}}$ process $^{2}$; and b) the existing DMP technology assessment process and criteria used to evaluate the DMP research and technology development portfolio and external technologies of interest since the start of the DMP in $2007^{3}$. The DMP DGP implements only those aspects of the TechSG ${ }^{\mathrm{TM}}$ that support decisions in the development timeframe of technologies for TRL 3-6.

\section{Purpose of Each Gate and Stage}

The objectives of the DGP are to review each task for its technical maturity, schedule status, ability to meet milestones within a given budget, determine the existence and extent of technical hurdles, and to ensure alignment with customer priority areas. The TRL definitions were expanded to delineate particular criteria that allow a determination of the technologies success to attain a certain TRL. Early in the development of the overall DGP, criteria were developed for each technology category (e.g. mechanical components and cleaning systems) to be used as a guideline for later definition of specific criteria for individual tasks.

The elements of the DGP flow include tasks (T), development stages (D), decision gates (G), and infusion points (I) as shown in Fig. 1. Tasks include individual technology development activities within the DMP that were to be developed to TRL 4, and later integrated with other technologies as part of an overall mitigation strategy for a particular application. Development stages are periods of technology development that lead to a decision gate. Development stages that lead to decision gates 3 and 4 represent single technology development efforts, while stages that lead to decision gates 5 and 6, as notated by an asterisk in Figure 1, represent the development and integration of multiple technologies that comprise an application area or mitigation strategy. Efforts occurring in each development stage were based on customized expectations of the TRL definitions, particular task objectives, and recommendations by the DGP review panel. Infusion points are defined as opportunities for a technology application or mitigation strategy to be integrated into a customer's system.

\section{Decision Gates}

The decision gate element of the process employs the assessment criteria to allow evaluation of a particular technology at each of the four TRLs noted previously. All decision gates function in the same way with the end result being one of four decisions: Continue, Redirect, Hold, or Terminate as illustrated in Fig. 2.

A set of decision gate evaluation criteria were developed that reflect the maturity, feasibility, and associated risk involved with the ability of a particular technology to reach and pass each decision gate. Evaluation criteria for decision gates 5 and 6 also address considerations related to integration, interoperability, and sustainment, which become equally important from a systems perspective in an operational environment. Since the technical community, DMP, and customer management were represented on the DGP review team, the results lent themselves to the basic decisions shown in Fig. 2. 


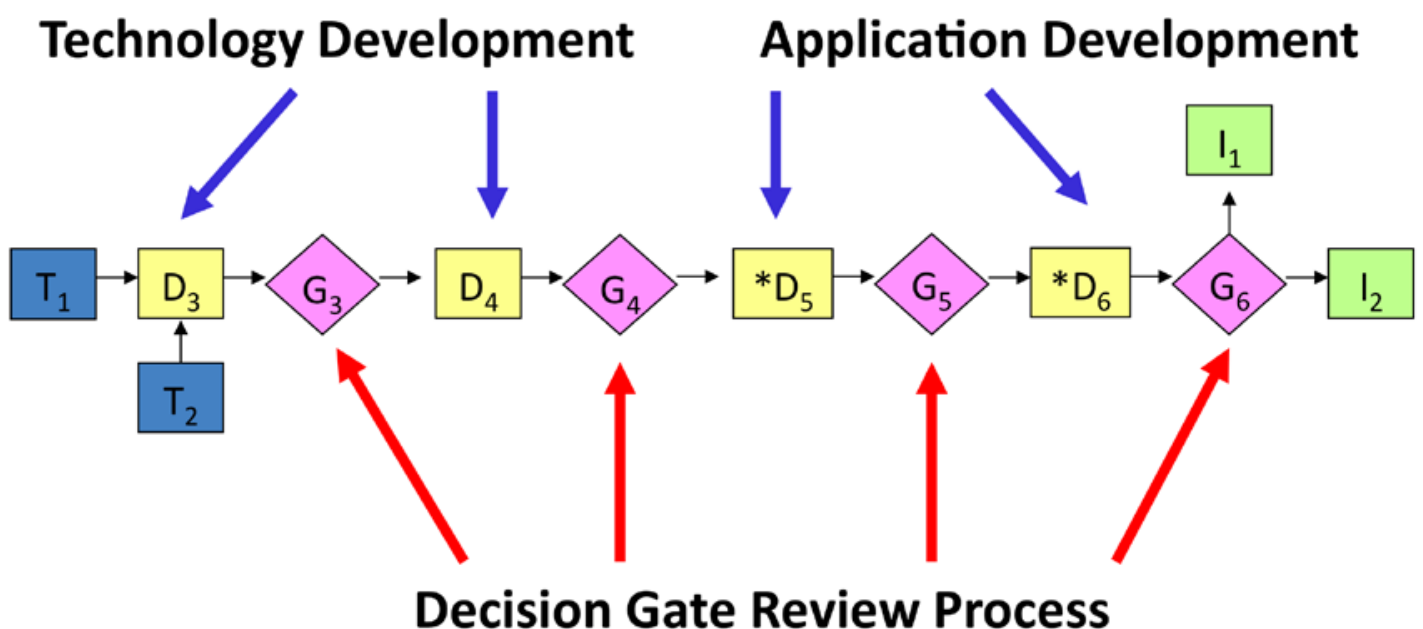

\section{T $=$ Task $\quad \mathbf{D}=$ Development Stage $\quad \mathbf{G}=$ Decision Gate $\quad \mathbf{I}=$ Infusion Point}

Figure 1. Decision gate process flow

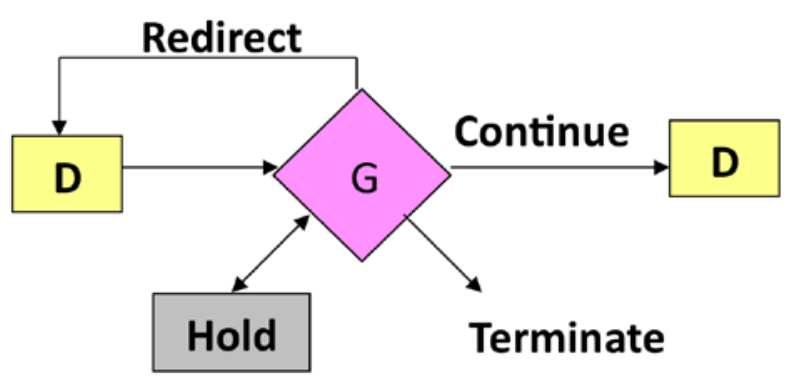

Figure 2. Typical decision gate with four possible decisions

As shown in Fig. 3, each DMP decision gate consists of three elements, or fundamental questions.

- Is this a "good" project?

The key questions to answer for this gate are: Does this technology satisfy the TRL for this gate? Does it have adequate resources and expertise dedicated to its success? This gate is evaluated from strategic, financial, and technical points of view. The DGP review team includes the necessary representatives to help evaluate the answer to these questions. At this point, a "sub-decision" is made. If the project is good, it continues to the next element. Otherwise the project is terminated.

- Is all information available?

The key question for this element: Is the task on schedule with achievable technical hurdles? The next sub-gate determines if the team has completed all the activities and deliverables in a quality fashion. This is important for a couple of reasons. First, if the task is not on schedule and activities are not completed, it becomes a risk to the completion of the project on time and within budget. Secondly, if the quality of the project deliverables is poor or lacking, it may hint at technical or management hurdles that may be insurmountable without redirection. In this element, the final decision is to either continue to the next sub-gate, or redirect the project to be evaluated again at the earlier element of the decision gate. 


\section{- Technology priority}

In this element, the key question is: What is the impact of the technology and the priority relative to other technologies? If the priority is high, the technology is supported and the project is continued. For a low priority verdict, there likely is a higher priority project that should be invested instead and the technology is placed on hold while another technology is evaluated for inclusion in the DMP portfolio. At this final sub-gate, the final element in the DGP is evaluated and completed and the project is given the green light to continue. Should the particular project pass all three elements, it would also pass the decision gate being evaluated.

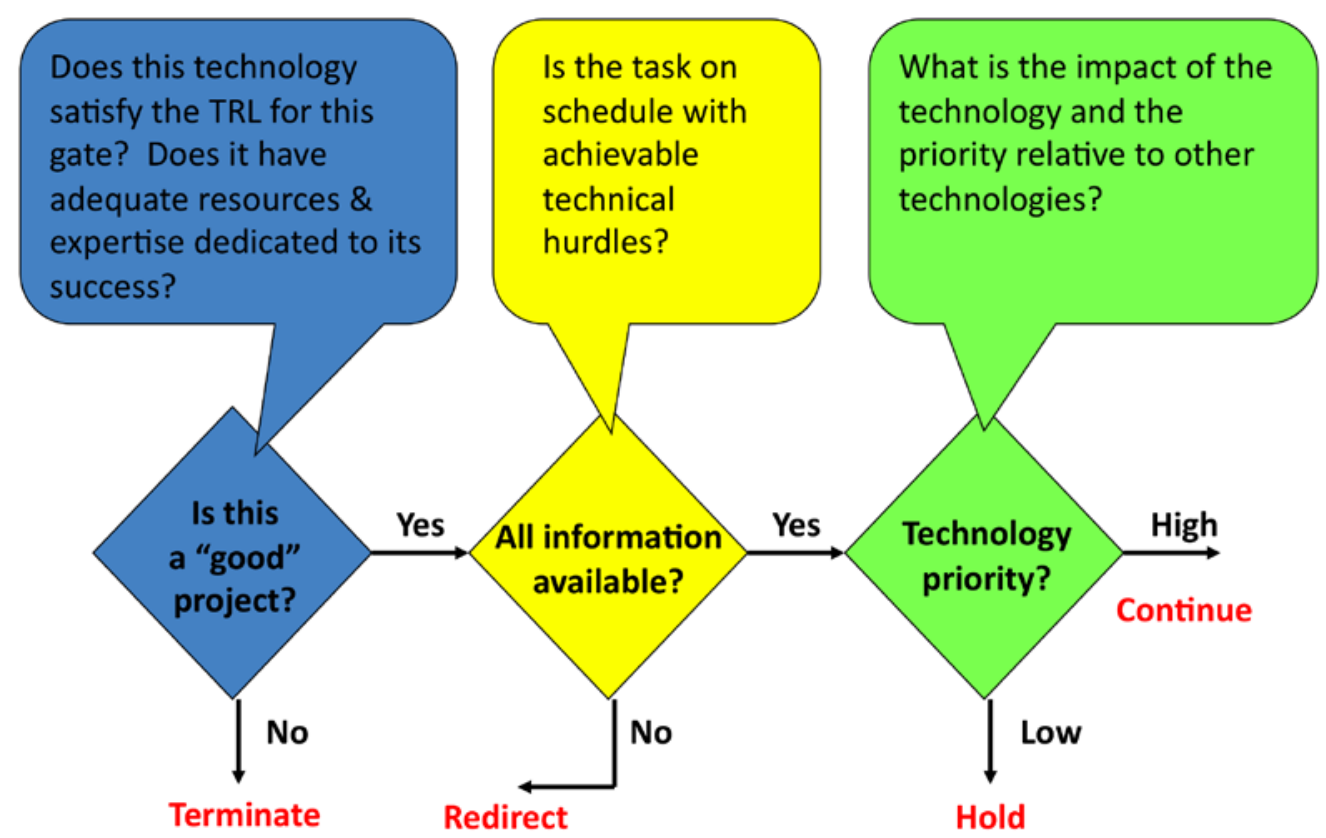

Figure 3. Decision gate criteria delineated to support an objective decision

The evaluation criteria developed for this assessment are prioritized and weighted for given decision gates in order to support an objective decision (Fig. 3). Decisions that are levied as products of the DGP are final and are to be implemented immediately to ensure a timely execution of the required action. Decisions to redirect or to hold the project are accompanied by explicit instructions for implementation by DMP Management.

Decision gates for each DMP technology and application were coordinated to occur prior to a customer milestone for which DMP technology validation was required. Additionally, each gate was established to review a particular technology or application upon the project reaching each TRL 3-6.

\section{B. Generic Implementation Approach}

The implementation of the DGP for DMP technology development and application areas consists of a sequence of steps. The order of these steps is listed below.

- Collect information on the project using prescribed data sheets

- Review and score the project by subject matter experts (SMEs)

- Review of the evaluation by the DGP review team

- Final decision made by the DGP review team

\section{Data Collection}

At the start of each decision gate, the project being reviewed provides detailed information (technical, schedule and cost) in the data sheet (Appendix A). The data sheet is reviewed for completeness by DMP Systems Engineering and Integration (SE\&I). Missing or supplementary information is obtained by follow up contact with the project lead.

\section{Technical Review and Scoring}

A technical SME performs an in-depth review of the information in the data sheet based on the assessment criteria in Appendix B, Technology Development Assessment Criteria, or Appendix C, Application Area 
Assessment Criteria. The level of fulfillment is determined for each criterion and a score is assigned. The weighted scores are summed and then averaged to obtain the final score for the technology or the application area. The scoring sheets are provided to the DGP review team. At the start of each decision gate, the project being reviewed provides detailed information (technical, schedule and cost) in the data sheet (Appendix A). The data sheet is reviewed for completeness by DMP Systems Engineering and Integration (SE\&I). Missing or supplementary information is obtained by follow up contact with the project lead.

\section{DGP Review Team Evaluation}

The DGP review team consists of the technical subject matter expert and project and customer management. This combination of team members allows for objective evaluation of the different technologies, based on scientific and technical maturity, feasibility, and relative need for the overall goals of the project. The SME presents the review and the scores for the technology at a meeting of the review team. The team evaluates the review and each member provides an opinion, based on the assessment criteria, level of fulfillment, and the scores, as well as assessing the overall potential of the project, assessing the risks involved and whether the risks can be mitigated, and other programmatic factors such as resource constraints (Fig. 3). The overall evaluation criteria, which are prioritized and weighted, are defined by the DGP review team. The team members also provide recommendations of the decision and the rationale for their individual decision regarding the project. The decision will be one of the four decisions in Fig. 3.

\section{Final DGP Decision}

The individual team member decisions are compiled as a data package by an executive secretary and are evaluated by the entire team. The decisions are counted by voice vote. The final decision (and any related conditions/clarifications) is communicated to DMP management, who, in turn, communicates the decision to the project lead.

\section{Description of Individual Steps in the Process Flow}

The application of the DGP to the DMP technology development and application areas follows the steps described above. A stepwise procedure is summarized below (Table 2) that describes an infrastructure for implementing each decision gate in terms of required tools, templates, venues, and participants, and defines the format and venue for reporting the DGP review team evaluation results to DMP management and to the technology developer.

Table 2. Individual Steps for Implementation of the DGP for DMP

\begin{tabular}{|c|l|l|l|}
\hline \multicolumn{1}{|c|}{ Title } & \multicolumn{1}{|c|}{ Description } & \multicolumn{1}{|c|}{ Infrastructure } \\
\hline \multicolumn{3}{|l|}{ General Planning Steps } \\
\hline 1 & $\begin{array}{l}\text { DGP kickoff } \\
\text { meeting }\end{array}$ & $\begin{array}{l}\text { The DGP review team kickoff meeting is by telecon. } \\
\text { Activities include: nomination of an executive secretary; } \\
\text { development of an agenda and schedule for the DGP; } \\
\text { approve the overall DGP plan; approve the list of SMEs. }\end{array}$ & Telecon information \\
\hline 2 & Identify SMEs & $\begin{array}{l}\text { SMEs are proposed in the DGP plan and approved by the } \\
\text { DGP review team. }\end{array}$ & None \\
\hline 3 & $\begin{array}{l}\text { Identify DGP } \\
\text { review team } \\
\text { members }\end{array}$ & $\begin{array}{l}\text { The DGP review team members are proposed and } \\
\text { approved by DMP Management (MGMT). }\end{array}$ & None \\
\hline
\end{tabular}




\begin{tabular}{|c|c|c|c|}
\hline Step & Title & Description & Infrastructure \\
\hline 4 & $\begin{array}{l}\text { Provide orientation } \\
\text { to the DGP }\end{array}$ & $\begin{array}{l}\text { The developers of the DGP plan provide an } \\
\text { orientation/training session to the DGP review team, } \\
\text { including instructions on the evaluation process, } \\
\text { assessment criteria, evaluation forms, and other logistics. } \\
\text { This session may be included in the kickoff meeting. }\end{array}$ & $\begin{array}{l}\text { 1. Data sheets } \\
\text { 2. Scoring forms } \\
\text { 3. DGP evaluation } \\
\text { criteria }\end{array}$ \\
\hline 5 & $\begin{array}{l}\text { Develop DGP } \\
\text { schedule }\end{array}$ & $\begin{array}{l}\text { The detailed DGP schedule for each technology and } \\
\text { application area is developed by the DGP review team to } \\
\text { meet the customer milestones. }\end{array}$ & None \\
\hline 6 & $\begin{array}{l}\text { Develop decision } \\
\text { gate evaluation } \\
\text { criteria }\end{array}$ & $\begin{array}{l}\text { Overall evaluation pass criteria for each decision gate are } \\
\text { approved by the DGP review team. These criteria may } \\
\text { include overall potential, project risks, and other } \\
\text { programmatic factors (resource constraints). }\end{array}$ & None \\
\hline \multicolumn{4}{|c|}{ Review Steps } \\
\hline 1 & $\begin{array}{l}\text { Collect project } \\
\text { information }\end{array}$ & $\begin{array}{l}\text { DMP SE\&I initiates contact with the project lead to collect } \\
\text { project information using the data sheet. }\end{array}$ & Data sheets \\
\hline 2 & $\begin{array}{l}\text { SME reviews data } \\
\text { sheet }\end{array}$ & $\begin{array}{l}\text { The SME performs a review of the data sheet for } \\
\text { completeness of the information. }\end{array}$ & Data sheets \\
\hline 3 & $\begin{array}{l}\text { SME follow up with } \\
\text { project lead (as } \\
\text { required) }\end{array}$ & $\begin{array}{l}\text { The SME follows up with the project lead to obtain any } \\
\text { missing or supplementary information as required. The } \\
\text { supplementary information is also recorded in a data sheet. }\end{array}$ & None \\
\hline 4 & $\begin{array}{l}\text { SME completes } \\
\text { review of project } \\
\text { information and } \\
\text { scoring }\end{array}$ & $\begin{array}{l}\text { The SME performs a detailed review of the project } \\
\text { information based on the assessment criteria and assigns } \\
\text { individual scores. This also includes the rationale for the } \\
\text { scores. The weighted score for the project is included in } \\
\text { the scoring sheet. The SME also includes a summary of } \\
\text { the review. }\end{array}$ & $\begin{array}{l}\text { 1. Data sheets } \\
\text { 2. Assessment criteria } \\
\text { and scoring sheets }\end{array}$ \\
\hline 5 & $\begin{array}{l}\text { Completed SME } \\
\text { review package } \\
\text { provided to DGP } \\
\text { review team }\end{array}$ & $\begin{array}{l}\text { The completed SME review package (data sheet and } \\
\text { supplements, scoring sheets, summary) is provided to each } \\
\text { DGP review team member at least } 2 \text { weeks prior to the } \\
\text { team evaluation meeting. }\end{array}$ & $\begin{array}{l}\text { 1. Review package } \\
\text { 2. Website/Docbase } \\
\text { for review upload }\end{array}$ \\
\hline 6 & $\begin{array}{l}\text { SME prepares } \\
\text { presentation for } \\
\text { DGP review team }\end{array}$ & $\begin{array}{l}\text { The SME prepares a presentation of the review for the } \\
\text { DGP review team. }\end{array}$ & Presentation template \\
\hline 7 & Team convenes & $\begin{array}{l}\text { The DGP review team convenes for the evaluation of the } \\
\text { project. The SME will present the detailed project review. } \\
\text { Each team member will provide comments and a summary } \\
\text { of the recommendation for the decision. This will be based } \\
\text { on the decision gate evaluation criteria. }\end{array}$ & $\begin{array}{l}\text { 1. Telecon } \\
\text { information } \\
\text { 2. SME review of } \\
\text { presentation } \\
\text { package }\end{array}$ \\
\hline 8 & $\begin{array}{l}\text { Evaluation data } \\
\text { package }\end{array}$ & $\begin{array}{l}\text { Each team member prepares a written summary of their } \\
\text { recommendation for the decision gate and the rationale for } \\
\text { the recommendation. The summary and the review data }\end{array}$ & $\begin{array}{l}\text { DGP evaluation data } \\
\text { package }\end{array}$ \\
\hline
\end{tabular}




\begin{tabular}{|c|l|l|c|}
\hline Step & \multicolumn{1}{|c|}{ Title } & \multicolumn{1}{c|}{ Description } & \multicolumn{1}{c|}{ Infrastructure } \\
\hline 9 & $\begin{array}{l}\text { package are provided to the DGP review team. } \\
\text { joint evaluation and } \\
\text { final decision }\end{array}$ & $\begin{array}{l}\text { The DGP review team meets for a team evaluation of the } \\
\text { project. The team evaluation is based on team review of } \\
\text { the individual evaluation data package. The final decision } \\
\text { is by voice vote of the team members. The final decision is } \\
\text { recorded in the minutes of the meeting. }\end{array}$ & $\begin{array}{l}\text { 1. } \\
\text { DGP evaluation } \\
\text { package }\end{array}$ \\
\hline 10 & $\begin{array}{l}\text { Decision } \\
\text { communication }\end{array}$ & $\begin{array}{l}\text { The DGP review team lead communicates the final } \\
\text { information } \\
\text { project lead. }\end{array}$ & None \\
\hline
\end{tabular}

\section{Assessment Criteria for DMP Technologies}

The criteria used for the DGP assessment of the DMP technologies are discussed in the following sections.

\section{Technology Readiness Levels}

The TRLs were the metric used to evaluate the maturity of the technologies developed for dust mitigation within the DMP. The key observation with regard to the TRL scale is that it only evaluates the maturity of an individual technology. TRL takes a given technology from basic principles to concept evaluation through to 'breadboard' validation, then to prototype demonstration, and finally to completion and successful mission operations.

For the DMP, the primary end objective of the technology development efforts at the originally planned completion of the DMP in 2016 was to successfully demonstrate a dust mitigation technology at TRL 6 that would meet the needs of the customer. At the same time for DGP assessments, the technology developments should each have matured at least to TRL 3 for typical lunar applications. This is a critical milestone and a decision gate for continued DMP support for each technology, since it is unlikely that the technology development projects and application areas could fully mature to TRL 6 before the projected completion of DMP in 2016. Therefore, the decision gates are assigned at TRL 3, TRL 4, TRL 5 and TRL 6, defined in Table 3.

Table 3. Definitions of NASA TRLs for DMP ${ }^{1}$

\begin{tabular}{|l|l|}
\hline \multicolumn{1}{|c|}{ TRL } & \multicolumn{1}{c|}{ Definition } \\
\hline $\begin{array}{l}\text { TRL 3 } 3 \text { Analical and } \\
\text { experimental critical } \\
\text { function and/or } \\
\text { characteristic proof-of- } \\
\text { concept }\end{array}$ & $\begin{array}{l}\text { At this step in the maturation process, active research and development (R\&D) } \\
\text { has been initiated. This must include both analytical studies to set the technology } \\
\text { into an appropriate context and laboratory-based studies to physically validate } \\
\text { that the analytical predictions are correct. These studies and experiments should } \\
\text { constitute "proof-of-concept" validation of the applications/concepts formulated } \\
\text { at the previous TRL 2. } \\
\text { Cost to achieve: low 'unique' cost (technology specific) }\end{array}$ \\
\hline $\begin{array}{l}\text { TRL 4 } \\
\text { Component and/or } \\
\text { in a laboard validation } \\
\text { environment. }\end{array}$ & $\begin{array}{l}\text { Following successful "proof-of-concept" work, basic technological elements } \\
\text { must be integrated to establish that the "pieces" will work together to achieve } \\
\text { concept-enabling levels of performance for a component and/or breadboard. This } \\
\text { validation must be devised to support the concept that was formulated earlier, and } \\
\text { should also be consistent with the requirements of potential system applications. } \\
\text { The validation is relatively "low-fidelity" compared to the eventual system: it } \\
\text { could be composed of ad hoc discrete components in a laboratory. } \\
\text { Cost to achieve: low-to-moderate 'unique' cost (investment will be technology } \\
\text { specific, but probably several orders greater than the investment required for } \\
\text { TRL 3) }\end{array}$ \\
\hline $\begin{array}{l}\text { TRL 5 } \\
\text { Component and/or } \\
\text { breadboard validation } \\
\text { in a relevant } \\
\text { environment. }\end{array}$ & $\begin{array}{l}\text { At this level, the fidelity of the component and/or breadboard being tested has to } \\
\text { increase significantly. The basic technological elements must be integrated with } \\
\text { reasonably realistic supporting elements so that the total applications (component } \\
\text { level, subsystem level, or system level) can be tested in a 'simulated' or } \\
\text { somewhat realistic environment (dust). From one-to-several new technologies }\end{array}$ \\
\hline
\end{tabular}




\begin{tabular}{|l|l|}
\hline \multicolumn{1}{|c|}{ TRL } & \multicolumn{1}{c|}{ Definition } \\
\hline & $\begin{array}{l}\text { might be involved in the demonstration. } \\
\text { Cost to achieve: moderate 'unique' cost (investment cost will be technology } \\
\text { dependent, but is likely to be several orders greater than the cost to achieve TRL } \\
\text { 4) }\end{array}$ \\
\hline $\begin{array}{l}\text { TRL 6 } \\
\text { System/subsystem } \\
\text { model or prototype } \\
\text { demonstration in a } \\
\text { relevant environment } \\
\text { (ground or space) }\end{array}$ & $\begin{array}{l}\text { A major step in the level of fidelity of the technology demonstration follows the } \\
\text { completion of TRL 5. At TRL 6, a representative model or prototype system or } \\
\text { system - which would go well beyond ad hoc, 'patch-cord' or discrete component } \\
\text { level breadboarding - would be tested in a relevant environment. At this level, if } \\
\text { the only 'relevant environment' is the environment of space, then the } \\
\text { model/prototype must be demonstrated in space. Of course, the demonstration } \\
\text { should be successful to represent a true TRL 6. Not all technologies will undergo } \\
\text { a TRL 6 demonstration: at this point the maturation step is driven more by } \\
\text { assuring management confidence than by R\&D requirements. The demonstration } \\
\text { might represent an actual system application, or it might only be similar to the } \\
\text { planned application, but using the same technologies. At this level, several-to- } \\
\text { many new technologies might be integrated into the demonstration. } \\
\text { Cost to achieve: technology and demonstration specific }\end{array}$ \\
\hline
\end{tabular}

While these characterizations are very useful in technology development, they say nothing about how a particular technology integrates within a complete system. Even at TRL 6, system-level demonstration is required (Table 3). Although the TRL includes no guidance into the uncertainty and risk in moving through the maturation of a TRL, it could be correlated to project risk and technological uncertainty for developing a project management framework.

\section{Technology Needs and Mapping}

The technology prioritization process (TPP) was an activity performed annually by the DMP's customer, the Constellation Program CxP). The TPP provided an opportunity for managers to capture and prioritize their technology needs across all projects and mission architectures. TPP results were ordered and ranked by mission architecture and priority. Due to the large number of potentially relevant needs related to dust management across the mission architectures, a subset of needs was selected by the DMP which represented both the highest ranked needs by the TPP and the needs that were closest to the focus of the DMP technology development tasks and the intended project scope. The subset of needs for the DMP is presented in Table 4. The DMP technology development tasks are mapped to dust-relevant TPP needs in Table 5.

\section{Assessment Criteria}

For assessing the current state of the technologies, a set of criteria were developed that reflect the maturity, feasibility, and associated risk involved with the ability of a particular technology to reach each TRL and pass the corresponding decision gate, and to eventually meet the DMP dust mitigation performance objectives. Certain criteria were ranked and weighted more heavily to reflect the applicability of the technology, and its potential impact, as well as the level of research and development effort required to mature the technology to the next TRL up to TRL 6. At a minimum, it was expected that the present technologies would have matured to TRL 3. Resourcerelated criteria (cost, schedule, and personnel, technical) were critical in meeting DMP budgets and schedules and were accordingly ranked and weighted high. Lower weights were attached to criteria reflecting the ability to develop hardware and delivery systems and the associated safety issues for actual application of the technology during a lunar mission, since most of the technologies and technology concepts were at very low readiness levels (TRL 1-3) for lunar missions.

Also included were evaluation criteria that addressed considerations relating to integration, interoperability, and sustainment which become equally important from a systems perspective in an operational environment. As noted earlier, these considerations are not addressed by the TRL.

Three levels of fulfillment were assigned from high to low for each criterion and a scoring range was provided to each fulfillment level. Appendices B and C list the criteria and their individual rank, the scoring range, and the weighting factor for the technology development and for application areas, respectively. When a technology has matured to TRL 6, the rank and weight for the criteria may be revised to more closely reflect DMP and customer requirements for space applications. At that point, mission specific readiness must be evaluated at TRL 7 to TRL $9^{1}$. 
Table 4. Summary of DMP Assessment Relevant TPP Dust Capability Needs

\begin{tabular}{|c|c|c|c|c|}
\hline TPP \# & Capability Title & CxP Project & $\begin{array}{c}\text { Mission } \\
\text { Architecture }\end{array}$ & Priority \\
\hline 344 & Automated lunar regolith cleaning systems & E\&C SIG & LS & HD \\
\hline 601 & Airlock /habitat hatches that are dust sealing & LSS & LS & $\mathrm{C}$ \\
\hline 609 & Dust mitigation of mechanical components & LSS & LS & $\mathrm{C}$ \\
\hline 611 & Dust-tolerant EVA-compatible connectors & LSS & LS & $\mathrm{C}$ \\
\hline 622 & $\begin{array}{l}\text { Environmentally robust electrical docking for rover } \\
\text { communications }\end{array}$ & LSS & LS & $\mathrm{C}$ \\
\hline 623 & Dust/Regolith mitigation techniques within habitable cabin & LSS & LS & $\mathrm{C}$ \\
\hline 625 & Dust control/remove airborne dust & LSS & LS & $\mathrm{C}$ \\
\hline 627 & Lander dust mitigation & LL & LT & HD \\
\hline 632 & $\begin{array}{l}\text { Long-life high-performance drive train and suspension } \\
\text { system }\end{array}$ & LSS & LS & $\mathrm{C}$ \\
\hline 633 & $\begin{array}{l}\text { Dust degradation effects and mitigation for thermal control } \\
\text { system }\end{array}$ & LSS & LS & $\mathrm{C}$ \\
\hline
\end{tabular}

Table 5. DMP Task Mapping to Assessment Relevant TPP Dust Capability Needs

\begin{tabular}{|l|c|}
\hline \multicolumn{1}{|c|}{ DMP Technology Development Task } & TPP Number \\
\hline Mechanical Components and Mechanisms & 609,632 \\
\hline Lotus Coatings & $601,623,625,627$ \\
\hline SPARCLED & $623,625,627$ \\
\hline $\mathrm{CO}_{2}$ Shower & $623,625,627$ \\
\hline Electrodynamic Dust Shield & $623,625,627$ \\
\hline Mitigation for Radiators & 633,627 \\
\hline Dust Tolerant EVA-Compatible Connectors & 611,622 \\
\hline
\end{tabular}

\section{Technology Scoring and Ranking}

For each DMP technology, detailed technical information on proof-of-concept demonstrations and other technical achievements, as well as project (cost and schedule performance) information was required in individual project data sheets. Each technology data sheet was reviewed in detail by subject matter experts for information related to the assessment criteria. In addition, engineering and scientific judgment was applied to the criteria for each technology, as well as personal knowledge of the current state-of-the-art for alternative technologies used for relevant or similar terrestrial applications. In the event the decision is reached to terminate an existing technology development project, alternative technologies would be reviewed as possible replacements. The alternative technologies would be assessed similarly through the DGP.

Based on the reviews, the level of fulfillment is determined for each criterion and a score is assigned from the range in Appendices B and C. Once a score is assigned to a criterion, it is multiplied by the weighting factor to obtain the weighted score for that criterion. The weighted scores are summed and then averaged to obtain the final score for the technology.

\section{Application of the Decision Gate Process to a DMP Technology}

The implementation of the DGP is illustrated by application to the $\mathrm{CO}_{2}$ snow shower technology.

\section{A. Overview}

The $\mathrm{CO}_{2}$ shower technology was selected for DGP assessment because it was claimed to be at the point of achieving TRL 3. Early implementation of the DGP to this technology at TRL 3 helped determine whether corrections or adjustments needed to be made. It also provided the opportunity to verify the implementation DGP 
and validate its application to the DMP technology portfolio. The process was applied as outlined in Sections 3.2 and 3.3.

The $\mathrm{CO}_{2}$ shower was assessed in December 2009 according to established technical and programmatic criteria that were scored and discussed by a review team comprised of MGMT, SE\&I, a SME in precision cleaning, and Constellation program customer representatives from the LSS, Environmental Control and Life Support Systems (ECLSS) and EVA projects. Specific DGP evaluation criteria (Appendix D) were developed for the $\mathrm{CO}_{2}$ shower technology within the general definition of TRL 3 to provide reviewers with a refined meaning of the TRL to allow more objectivity in the assessment, and to assist in scoring the technologies. Other criteria included availability of resources, technical hurdles to be overcome for successive TRLs, expertise of the task team, and the priority of the technology. The DGP evaluation criteria were broader than the technology assessment criteria.

The review team members scored the DGP evaluation criteria according to three levels of fulfillment with ranges for High (67-100), Moderate (34-66) and Low (0-33). The delineation of particular criteria and the associated scoring component of the DGP were meant to support the final voice vote of each review team member. Scores were calculated per the weighting factor of each criterion.

\section{B. Assessment of the Technology}

The review team members convened for the assessment of the $\mathrm{CO}_{2}$ snow shower technology starting with the SME presenting an overview of the technology and discussing his assessment, based on the criteria in Appendix B. The purpose of this technical assessment was to provide reviewers who were not experts in the removal of small particles, or the $\mathrm{CO}_{2}$ snow shower, with supplemental technical knowledge on the technology itself or a category of related technologies from the perspective of an expert in the field. Several questions and issues were discussed during the course of the overview of the technology.

1. The criteria used by the SME during his technical assessment are organized differently to allow for more discussion of the specific technical details of the technology. The review team could choose to use the technical expert's results to supplement their own expertise as they considered how to score the technical aspects of the technology.

2. The $\mathrm{CO}_{2}$ shower has a critical dependency on successfully integrating with the EDS technology for dust particle removal to be useful as an integrated dust mitigation system. Even though no requirement for the removal of sub- $\mu \mathrm{m}$ to $10-\mu \mathrm{m}$ size particles exists for EVA, these two technologies may have been synergistic pending test results that identify the smallest particle size that the EDS can remove as a stand-alone technology. The $\mathrm{CO}_{2}$ shower may have effectively extended the lower limit of the EDS applicable size range for particle removal, but technology developers would need to know the effective particle size range for the EDS to determine how large a crystal would need to grow for the EDS to remove it. Several concerns were expressed with the $\mathrm{CO}_{2}$ shower both as a stand-alone technology and as integrated with the EDS:

a. The EDS works on a non-charged particle as the EDS self induces a charged state on the particle prior to removal. Tests at the time of the review had not determined whether the EDS can induce surface charge characteristics when $\mathrm{CO}_{2}$ crystals have grown onto particles. The task lead indicated that the $\mathrm{CO} 2$ may itself need to be charged.

b. The amount of $\mathrm{CO}_{2}$ required for the shower to function scales with the volume of the chamber that is used for the shower. The task lead had not indicated that $\mathrm{CO}_{2}$ needs to be recovered or recycled. The LSS customer representative for ECLSS noted that the amount of $\mathrm{CO}_{2}$ required (approximately $0.2 \mathrm{~m} 3$ for a shower volume of $2 \mathrm{~m} 3$ ) is not a small amount.

c. Folds in the outer layers of the EVA suit are a concern as the $\mathrm{CO}_{2}$ shower is a line-of-sight process. It will need to be determined how critical is it to remove dust from all areas of the suit.

d. There are 2 architectures under consideration that affect potential EVA dust mitigation/management technologies. For both architectures, routine switch-out of the suits would be the biggest issue for dust mitigation.

I. SuitPort - Suits would remain outside all the time and would not have to be brought into the habitat itself.

II. SuitLock - Suits would remain in the airlock and may be bagged if they need to be brought into the habitat.

e. A successful proof-of-concept milestone for the $\mathrm{CO}_{2}$ shower was achieved by growing crystals on a glass slide contaminated with small particles. However, no tests had been performed to show that crystals will grow on an EDS, which would be representative of TRL 3.

f. A set of experiments would have to be designed to show that crystals can grow to a suitable size and not be affected by mechanical movement or not collapse under their own weight. 


\section{Review Team Recommendations}

The final recommendation was given by voice vote. Based on the team member evaluations, the technology scored low which would normally support a final voice vote for TERMINATION of the project. However, the technology was not yet demonstrated at TRL 3 and the review team rendered a recommendation of REDIRECT with the following conditions.

- REDIRECT ${ }^{5}$ only allowed completion of TRL 3 experiments to achieve the definition for this decision gate with no additional financial resources.

- $\mathrm{CO}_{2}$ shower technology would need to be demonstrated integrated with an EDS.

- The task lead would need to develop a near-term schedule complete with a test matrix indicating test frequency, materials used, and interim task-internal go/no-points. The schedule would not exceed 6 months, with a preference for completion in less than 3 months.

- The review team would need to reconvene for a delta decision gate for TRL 3 when the task lead indicates he has achieved TRL 3.

One additional point of consideration is that it would be difficult to evaluate the suitability and applicability of $\mathrm{CO}_{2}$ shower technology, and the DMP technologies in general, until it is decided 'how clean is clean enough'.

\section{Lessons Learned}

Over the course of development and implementation of the DGP for use by the DMP, the following points are taken as lessons learned for future related activities.

- Timely application of DGP is essential to assess the technology and make appropriate project adjustments (technical, cost and schedule) to meet the overall end objectives.

- It is important to have consistent evaluation criteria for objective assessment of the technology.

- The technology must be developed to meet customer needs, rather than conducting a technology development project without a well-established application for the technology.

\section{Summary and Conclusions}

The development and implementation of a decision gate process has been described. The DGP was a critical element of DMP risk management to validate the achievement and priority of each DMP technology as it progressed through its development cycle. At the core of the process are technology-specific criteria developed to measure the success of each technology in attaining the TRLs assigned to each decision gate. In all, four decision gates were delineated with TRL 3 and 4 assigned and adapted to DMP technology development tasks and TRL 5 and 6 assigned and adapted to DMP technology application areas.

The DMP technology development portfolio consisted of different categories of technologies whose final product was either a technology solution itself, or one that contributed toward a dust mitigation strategy for a particular application. As described here, the DGP accounts for both categories and qualifies the technology progression from development to application. The process supports customer milestones by providing opportunities to validate performance as well as identify non-performance in time to adjust resources and direction.

The overall philosophy and methodology of the DGP for the DMP technologies has been discussed, and the core evaluation criteria for each technology category and specific criteria for each technology by TRL were defined. The detailed steps in the implementation of the DGP for each decision gate and the supporting infrastructure for implementing the process in terms of required tools, templates, venues, and participants have been described. Review of the CO2 snow shower technology has been used to illustrate the implementation of the DGP and its application to a DMP technology. The process is applicable to future NASA technology development projects.

\footnotetext{
${ }^{5}$ REDIRECT may have allowed for an orderly closure of the task at no additional cost to the DMP. Data collected during REDIRECT efforts may also justify termination in the future.
} 


\section{Appendix A \\ DMP DGP Technology Data Sheet}

\section{General Information}

- Technology Title:

- Description:

- Contact Information (Lead Center, Supporting Centers, External Partners):

\section{Applicability to Dust Needs and Requirements}

Indicate the applicable dust need(s) that this technology or research addresses and indicate the degree of potential applicability (Low (L), Moderate (M), High $(\mathrm{H})$ ) toward meeting/supporting each need (Select needs from the Integrated Dust Needs sheet)

- Need ID \# _ : Circle or Highlight Low-Mod-High

- How does the technology or research apply/support?

- Need ID \#_ _: Circle or Highlight Low-Mod-High

- How does the technology or research apply/support?

- Need ID \#_ : Circle or Highlight Low-Mod-High

- How does the technology or research apply/support?

\section{For Technology Tasks:}

- Describe the potential use scenario and configuration of the technology.

- Suggest specifications and characteristics of the applied technology to effectively mitigate/manage dust for -

- Lunar application:

- Martian application:

\section{Developmental / Knowledge Infusion Profile} For Technology Tasks:

- Current NASA TRL:

- Estimate a reasonable NASA TRL progression profile (calendar year) assuming requested funding and optimal development schedule:

TRL 3: TRL 4: TRL 5: TRL 6:

- Estimate the probability (Low (L), < 50\%; Moderate (M), 50\% - 80\%; High, >80\%) of the technology maturing to TRL 6 in the following future years (system PDRs) assuming requested funding and optimal development schedule:

2010: 2011: 2012: 2013: 2014:

- Describe the major developmental hurdles/issues at each NASA TRL. Indicate decision point (go/no-go) for further efforts.

TRL 3 -

TRL 4 -

TRL 5 -

TRL 6 - 
- $\quad$ List any assumptions or known dependencies.

\section{Supporting Vehicle/Infrastructure Needs and Assumptions:}

For each, discuss anticipated performance improvements, as applicable, for both technology and research tasks.

- Describe significant system or other dependencies, integration issues, or operating assumptions:

- $\quad$ Estimated Power Demands -

- $\quad$ Estimated Mass -

- $\quad$ Estimated Volume -

- $\quad$ Crew Time (Hours per week) Assume 3 EVAs/week

\section{Leveraging Opportunities}

- $\quad$ Describe current and projected non-NASA applications (or research in applicable areas) that may enable or accelerate the development of the technology or research objective independent of investment by NASA.

- Identify Potential Leveraging or Collaborative Activities, and/or Vendors:

\section{Estimate Technology/Research Costs}

- $\quad$ For Technology Tasks: Provide an estimate of development costs to achieve TRL 6. Provide cost by TRL and year.

FY10: TRL

FY11: TRL

FY12:_ TRL

FY13: $\quad$ TRL

FY14:

- $\quad$ For Research Tasks: Provide an estimate of costs to meet research objective(s):

Provide cost by objective and year.

\section{Please provide other relevant information not captured in 1 - 6 above}


Appendix B

\begin{tabular}{|c|c|c|c|c|c|c|}
\hline \multicolumn{7}{|c|}{ DMP Technology Development Assessment Criteria } \\
\hline \multirow[b]{2}{*}{ No. } & \multirow[b]{2}{*}{ Criteria } & \multicolumn{3}{|c|}{ Rating } & \multirow[b]{2}{*}{ Rank } & \multirow{2}{*}{$\begin{array}{l}\text { Weighting } \\
\text { Factor }\end{array}$} \\
\hline & & $\begin{array}{c}\text { High } \\
\text { Score: } 67-100\end{array}$ & $\begin{array}{c}\text { Moderate } \\
\text { Score: } 34-66\end{array}$ & $\begin{array}{c}\text { Low } \\
\text { Score: } 0-33 \\
\end{array}$ & & \\
\hline 1 & $\begin{array}{l}\text { DMP Needs addressed } \\
\text { a. Number } \\
\text { b. Type }\end{array}$ & $\begin{array}{l}\text { a. Multiple needs addressed or full } \\
\text { intent of single need addressed } \\
\text { b. Short-term and long-term }\end{array}$ & $\begin{array}{l}\text { a. Few needs addressed } \\
\text { b. Mainly short term }\end{array}$ & $\begin{array}{l}\text { a. Single need addressed } \\
\text { b. Mainly short term }\end{array}$ & 1 & 1.0000 \\
\hline 2 & Technology Readiness Level (TRL) & TRL: 6 and higher & TRL: 3 to 5 & TRL: below 3 & 2 & 0.9000 \\
\hline 3 & Technology Impact Level & $\begin{array}{l}\text { a. Technology/research required to } \\
\text { meet mission/system objectives } \\
\text { b. Technology/research has major } \\
\text { impact on meeting mission/system } \\
\text { objectives. }\end{array}$ & $\begin{array}{l}\text { Technology/research has } \\
\text { some impact on meeting } \\
\text { mission/system objectives. }\end{array}$ & $\begin{array}{l}\text { Technology/research has a } \\
\text { minor impact on meeting } \\
\text { mission/system objectives. }\end{array}$ & 3 & 0.8000 \\
\hline 4 & $\begin{array}{l}\text { Development effort to achieve next TRL level } \\
\begin{array}{l}\text { a. Required or not required } \\
\text { b. Degree of difficulty }\end{array}\end{array}$ & $\begin{array}{l}\text { a. Minimal or no development } \\
\text { b. Very low degree of difficulty } \\
\text { anticipated to meet end objectives. } \\
\text { Probability of success } \geq 99 \% \text {. }\end{array}$ & $\begin{array}{l}\text { a. Moderate development } \\
\text { effort required } \\
\text { b. High degree of difficulty } \\
\text { anticipated to meet end } \\
\text { objectives. Probability of } \\
\text { success } 50 \text { to } 98 \% \text {. }\end{array}$ & \begin{tabular}{|l|} 
a. Intensive development \\
effort required \\
b. Very high degree of \\
difficulty anticipated to meet \\
end objectives. Probability of \\
success $<50 \%$.
\end{tabular} & 4 & 0.7000 \\
\hline 5 & $\begin{array}{l}\text { Resources } \\
\text { a. Cost (personnel, capital, materials, infrastructure, } \\
\text { travel) } \\
\text { b. Availability and allocation }\end{array}$ & $\begin{array}{l}\text { a. Low } \\
\text { b. High (limited interference with } \\
\text { other projects) }\end{array}$ & $\begin{array}{l}\text { a. Moderate } \\
\text { b. Moderate (some } \\
\text { interference with other } \\
\text { projects) }\end{array}$ & $\begin{array}{l}\text { a. High } \\
\text { b. Low (significant interference } \\
\text { with other projects) }\end{array}$ & 5 & 0.6000 \\
\hline 6 & $\begin{array}{l}\text { Performance improvement } \\
\text { a. Improvement (or contributes to improvement) over } \\
\text { current state-of-the-art (SOA) based on applicable } \\
\text { figures of merit (FOM), such as reduction in } \\
\text { percentage of crew time, up mass (weight/volume), } \\
\text { power requirements } \\
\text { b. FOM appl }\end{array}$ & $\begin{array}{l}\text { a. Significant improvement versus } \\
\text { current SOA } \\
\text { b. High FOM }\end{array}$ & $\begin{array}{l}\text { a. Some improvement versus } \\
\text { current SOA } \\
\text { b. Moderate FOM }\end{array}$ & $\begin{array}{l}\text { a. Minor improvement versus } \\
\text { current SOA } \\
\text { b. Low FOM }\end{array}$ & 6 & 0.5000 \\
\hline 7 & $\begin{array}{l}\text { Technical experience } \\
\text { a. Team composition, technical background and skills }\end{array}$ & a. High & a. Moderate & a. Low & 7 & 0.4000 \\
\hline 8 & $\begin{array}{l}\text { Project Management (PM) } \\
\text { a. Prior experience of the organization and the } \\
\text { management and technical team } \\
\text { b. Controls (budget and schedule, milestones, } \\
\text { decision gates and deliverable products) }\end{array}$ & $\begin{array}{l}\text { a. Extensive PM experience } \\
\text { b. Well defined project controls }\end{array}$ & $\begin{array}{l}\text { a. Moderate PM experience } \\
\text { b. Limited project controls }\end{array}$ & $\begin{array}{l}\text { a. Limited or no formal PM } \\
\text { experience } \\
\text { b. Minimal project controls }\end{array}$ & 8 & 0.3000 \\
\hline 9 & $\begin{array}{l}\text { Mission applicability } \\
\text { a. Types of missions (Transit, Lunar sortie, Lunar } \\
\text { outpost) } \\
\text { b. Versatility for a specific mission }\end{array}$ & $\begin{array}{l}\text { a. Meets multiple missions } \\
\text { b. Versatility for multiple aspects of a } \\
\text { single mission or applicable to } \\
\text { multiple missions }\end{array}$ & $\begin{array}{l}\text { a. Meets one type of mission } \\
\text { only } \\
\text { b. Limited versatility to a } \\
\text { single aspect of a single } \\
\text { mission or applicable to single } \\
\text { mission }\end{array}$ & $\begin{array}{l}\text { a. Meets one type of mission } \\
\text { only } \\
\text { b. No versatility }\end{array}$ & 9 & 0.2000 \\
\hline 10 & $\begin{array}{l}\text { Benefit from other similar technology } \\
\text { development programs } \\
\text { a. NASA } \\
\text { b. Non-NASA }\end{array}$ & $\begin{array}{l}\text { a. Significant leverage off NASA } \\
\text { programs; or not required } \\
\text { b. Significant leverage off non-NASA } \\
\text { programs; or not required }\end{array}$ & $\begin{array}{l}\text { a. Some leverage off NASA } \\
\text { programs } \\
\text { b. Minimal leverage off non- } \\
\text { NASA programs }\end{array}$ & $\begin{array}{l}\text { a. Minimal leverage off NASA } \\
\text { programs } \\
\text { b. Minimal leverage off non- } \\
\text { NASA programs }\end{array}$ & 10 & 0.1000 \\
\hline
\end{tabular}


Appendix C

\begin{tabular}{|c|c|c|c|c|c|c|}
\hline \multicolumn{7}{|c|}{ DMP Application Area Assessment Criteria } \\
\hline \multirow[b]{2}{*}{ No. } & \multirow[b]{2}{*}{ Criteria } & \multicolumn{3}{|c|}{ Rating } & \multirow[b]{2}{*}{ Rank } & \multirow{2}{*}{$\begin{array}{l}\text { Weighting } \\
\text { Factor }\end{array}$} \\
\hline & & $\begin{array}{c}\text { High } \\
\text { Score: } 67-100\end{array}$ & $\begin{array}{c}\text { Moderate } \\
\text { Score: } 34-66\end{array}$ & $\begin{array}{c}\text { Low } \\
\text { Score: } 0 \text { - } 33\end{array}$ & & \\
\hline 1 & $\begin{array}{l}\text { DMP Needs addressed } \\
\text { a. Number } \\
\text { b. Type }\end{array}$ & $\begin{array}{l}\text { a. Multiple needs addressed or } \\
\text { full intent of single need } \\
\text { addressed } \\
\text { b. Short-term and long-term }\end{array}$ & $\begin{array}{l}\text { a. Few needs addressed } \\
\text { b. Mainly short term }\end{array}$ & $\begin{array}{l}\text { a. Single need addressed } \\
\text { b. Mainly short term }\end{array}$ & 1 & 1.0000 \\
\hline 2 & Application TRL & TRL: 6 and higher & TRL: between 5 and 6 & TRL: 5 or lower & 2 & 0.9000 \\
\hline 3 & Impact Level & $\begin{array}{l}\text { Application has major impact on } \\
\text { meeting mission/system } \\
\text { objectives. }\end{array}$ & $\begin{array}{l}\text { Application has some } \\
\text { impact on meeting } \\
\text { mission/system objectives. }\end{array}$ & $\begin{array}{l}\text { Application has a minor impact } \\
\text { on meeting mission/system } \\
\text { objectives. }\end{array}$ & 3 & 0.8000 \\
\hline 4 & $\begin{array}{l}\text { Development effort to achieve next TRL } \\
\text { level } \\
\text { a. Required or not required } \\
\text { b. Degree of difficulty }\end{array}$ & $\begin{array}{l}\text { a. Minimal or no development } \\
\text { b. Very low degree of difficulty } \\
\text { anticipated to meet end } \\
\text { objectives. Probability of } \\
\text { success } \geq 99 \% \text {. }\end{array}$ & $\begin{array}{l}\text { a. Moderate development } \\
\text { effort required } \\
\text { b. High degree of difficulty } \\
\text { anticipated to meet end } \\
\text { objectives. Probability of } \\
\text { success } 50 \text { to } 98 \% \text {. }\end{array}$ & $\begin{array}{l}\text { a. Intensive development effort } \\
\text { required } \\
\text { b. Very high degree of difficulty } \\
\text { anticipated to meet end } \\
\text { objectives. Probability of } \\
\text { success }<50 \% \text {. }\end{array}$ & 4 & 0.7000 \\
\hline 5 & $\begin{array}{l}\frac{\text { Resources }}{\text { a. Cost (personnel, capital, materials, }} \\
\text { infrastructure, travel) } \\
\text { b. Availability and allocation }\end{array}$ & $\begin{array}{l}\text { a. Low } \\
\text { b. High (limited interference } \\
\text { with other projects) }\end{array}$ & $\begin{array}{l}\text { a. Moderate } \\
\text { b. Moderate (some } \\
\text { interference with other } \\
\text { projects) }\end{array}$ & $\begin{array}{l}\text { a. High } \\
\text { b. Low (significant interference } \\
\text { with other projects) }\end{array}$ & 5 & 0.6000 \\
\hline 6 & $\begin{array}{l}\text { Project Management (PM) } \\
\text { a. Prior experience of the organization and the } \\
\text { management and technical team } \\
\text { b. Controls (budget and schedule, milestones, } \\
\text { decision gates and deliverable products) }\end{array}$ & $\begin{array}{l}\text { a. Extensive PM experience } \\
\text { b. Well defined project controls }\end{array}$ & $\begin{array}{l}\text { a. Moderate PM experience } \\
\text { b. Limited project controls }\end{array}$ & $\begin{array}{l}\text { a. Limited or no formal PM } \\
\text { experience } \\
\text { b. Minimal project controls }\end{array}$ & 6 & 0.5000 \\
\hline 7 & $\begin{array}{l}\text { Integration with other systems - } \\
\text { infrastructure, utilities, output } \\
\text { management } \\
\text { a. Dependency } \\
\text { b. Degree of difficulty }\end{array}$ & $\begin{array}{l}\text { a. No multiple interaction } \\
\text { between systems } \\
\text { b. Minimal difficulty }\end{array}$ & $\begin{array}{l}\text { a. Some multiple } \\
\text { interaction between } \\
\text { systems } \\
\text { b. Moderate difficulty in } \\
\text { integration }\end{array}$ & $\begin{array}{l}\text { a. Significant multiple } \\
\text { interaction between systems } \\
\text { b. High degree of difficulty in } \\
\text { integration }\end{array}$ & 7 & 0.4000 \\
\hline 8 & $\begin{array}{l}\text { Safety, Reliability, Quality and } \\
\text { Maintainability } \\
\text { a. Ease of design for low risk and hazard controls } \\
\text { b. Achieves improvement }\end{array}$ & a. High & a. Moderate & a. Low & 8 & 0.3000 \\
\hline 9 & $\begin{array}{l}\text { Technical experience } \\
\begin{array}{l}\text { a. Team composition, technical background and } \\
\text { skills }\end{array}\end{array}$ & a. High & a. Moderate & a. Low & 9 & 0.2000 \\
\hline 10 & $\begin{array}{l}\text { Mission applicability } \\
\text { a. Types of missions (Transit, Lunar sortie, Lunar } \\
\text { outpost) } \\
\text { b. Versatility for a specific mission }\end{array}$ & $\begin{array}{l}\text { a. Meets multiple missions } \\
\text { b. Versatility for multiple } \\
\text { aspects of a single mission or } \\
\text { applicable to multiple missions }\end{array}$ & $\begin{array}{l}\text { a. Meets one type of } \\
\text { mission only } \\
\text { b. Limited versatility to a } \\
\text { single aspect of a single } \\
\text { mission or applicable to } \\
\text { single mission }\end{array}$ & $\begin{array}{l}\text { a. Meets one type of mission } \\
\text { only } \\
\text { b. No versatility }\end{array}$ & 10 & 0.1000 \\
\hline
\end{tabular}


Appendix D

\begin{tabular}{|c|c|c|c|c|c|c|}
\hline \multicolumn{7}{|c|}{ Decision Gate Evaluation Criteria } \\
\hline \multirow[b]{2}{*}{ No. } & \multirow[b]{2}{*}{ Criteria } & \multicolumn{3}{|c|}{ Rating } & \multirow[b]{2}{*}{ Rank } & \multirow{2}{*}{$\begin{array}{l}\text { Weighting } \\
\text { Factor }\end{array}$} \\
\hline & & $\begin{array}{c}\text { High } \\
\text { Score: } 67-100 \\
\end{array}$ & $\begin{array}{c}\text { Moderate } \\
\text { Score: } 34-66 \\
\end{array}$ & $\begin{array}{c}\text { Low } \\
\text { Score: } 0-33 \\
\end{array}$ & & \\
\hline \multicolumn{7}{|c|}{ Sub-gate 1: Is this a "good" project? } \\
\hline 1 & $\begin{array}{l}\text { Technical assessment } \\
\text { a. SME Review and Score } \\
\text { b. Meets TRL for this gate }\end{array}$ & $\begin{array}{l}\text { a. High } \\
\text { b. Yes }\end{array}$ & $\begin{array}{l}\text { a. Medium } \\
\text { b. Yes (conditionally) }\end{array}$ & $\begin{array}{l}\text { a. Low } \\
\text { b. No }\end{array}$ & 1 & 0.50 \\
\hline 2 & $\begin{array}{l}\text { Resources } \\
\text { a. Adequacy (personnel, equipment and facilities) } \\
\text { b. Availability and allocation }\end{array}$ & $\begin{array}{l}\text { a. High } \\
\text { b. Well planned and supported }\end{array}$ & $\begin{array}{l}\text { a. Medium } \\
\text { b. Medium level support }\end{array}$ & $\begin{array}{l}\text { a. Low } \\
\text { b. Limited support }\end{array}$ & 2 & 0.50 \\
\hline \multicolumn{7}{|c|}{ Sub-gate 2: Is all information available? } \\
\hline 1 & \begin{tabular}{|l} 
Technical hurdles \\
a. Number and type \\
b. Degree of difficulty to overcome
\end{tabular} & $\begin{array}{l}\text { a. Low, mostly engineering hurdles } \\
\text { b. Low }\end{array}$ & $\begin{array}{l}\text { a. Medium, some basic and some } \\
\text { engineering hurdles } \\
\text { b. Moderate }\end{array}$ & $\begin{array}{l}\text { a. High, many basic and } \\
\text { engineering hurdles } \\
\text { b. High }\end{array}$ & 1 & 1.00 \\
\hline 2 & $\begin{array}{l}\text { Project Management (PM) } \\
\text { a. Status (milestones achieved, products delivered) } \\
\text { b. Controls (budget and schedule) }\end{array}$ & $\begin{array}{l}\text { a. Large number }(>80 \%) \\
\text { b. Well defined project controls }\end{array}$ & $\begin{array}{l}\text { a. Medium number (50 to } 80 \% \text { ) } \\
\text { c. Limited project controls }\end{array}$ & $\begin{array}{l}\text { a. Low number (<50\%) } \\
\text { b. Minimal project controls }\end{array}$ & 2 & 0.67 \\
\hline 3 & $\begin{array}{l}\text { Risk Assessment } \\
\text { a. Technical } \\
\text { b. Cost } \\
\text { c. Schedule }\end{array}$ & $\begin{array}{l}\text { a. Low } \\
\text { b. Low } \\
\text { c. Low }\end{array}$ & $\begin{array}{l}\text { a. Medium } \\
\text { b. Medium } \\
\text { c. Medium }\end{array}$ & $\begin{array}{l}\text { a. High } \\
\text { b. High } \\
\text { c. High }\end{array}$ & 3 & 0.33 \\
\hline \multicolumn{7}{|c|}{ Sub-gate 3: Technology Priority } \\
\hline 1 & \begin{tabular}{|l|} 
Project Impact \\
$\begin{array}{l}\text { a. DMP/customer needs addressed } \\
\text { b. Critical support for other DMP technologies }\end{array}$ \\
\end{tabular} & \begin{tabular}{|l|}
$\begin{array}{l}\text { a. Multiple needs addressed or full } \\
\text { intent of single need addressed } \\
\text { (short term and long term) } \\
\text { b. Yes }\end{array}$ \\
\end{tabular} & $\begin{array}{l}\text { a. Few mainly short-term needs } \\
\text { addressed } \\
\text { b. Maybe }\end{array}$ & $\begin{array}{l}\text { a. Single need (mainly short } \\
\text { term) addressed } \\
\text { b. No }\end{array}$ & 1 & 0.50 \\
\hline 2 & $\begin{array}{l}\text { Project Priority } \\
\text { a. Degree of relevance to DMP/customer } \\
\text { b. Priority relative to other technologies (alternative) }\end{array}$ & $\begin{array}{l}\text { a. High } \\
\text { b. High }\end{array}$ & $\begin{array}{l}\text { a. Medium } \\
\text { b. Medium }\end{array}$ & $\begin{array}{l}\text { a. Low } \\
\text { b. Low }\end{array}$ & 2 & 0.50 \\
\hline
\end{tabular}

\section{Disclaimer}

All trademarks, service marks, and trade names are the property of their respective owners.

\section{References}

${ }^{1}$ Mankins, J. C., “Technology Readiness Levels - A White Paper,” NASA Office of Space Access and Technology, Washington, DC, April 2005.

${ }^{2}$ Ajamian, G. M., and Koen, P. A., “Technology Stage-Gate ${ }^{\mathrm{TM}}$ : A Structured Process for Managing High-Risk New Technology Projects,” The PDMA Toolbook for New Product Development, edited by P. Belliveau, A. Griffin, and S. Somermeyer, Vol. 1, John Wiley \& Sons, New York, 2002, pp. 267-295.

${ }^{3}$ Kohli, R., Fishman, J. L., Hyatt, M. J., Abel, P., and Delaune, P. B., “Achieving a Prioritized Research \& Technology Development Portfolio for the Dust Management Project," IEEE 2009 Aerospace Conference Proceedings [CD-ROM], Paper 1043, IEEE, Washington, DC, 2009. 